\title{
Management of post-earthquake construction debris in Tehran Metropolitan
}

\author{
L. Askarizadeh ${ }^{1}$ A. R. Karbassi ${ }^{2}$ M. B. Ghalibaf ${ }^{3}$ J. Nouri ${ }^{1}$
}

Received: 29 June 2015/Revised: 12 September 2015/Accepted: 21 September 2015/Published online: 2 November 2015

(C) Islamic Azad University (IAU) 2015

\begin{abstract}
Earthquakes can lead to different levels of damages and subsequently produce significant volume of debris. Management of such huge amount of debris needs special attention. Thus, it is vital to develop a comprehensive and cost-effective management plan. The present study was carried out to estimate post-earthquake debris volume in the 22 districts of Tehran under various earthquake scenarios [magnitudes of $5,6.5$, and 7.5 on the moment magnitude $\left(M_{\mathrm{W}}\right)$ scale]. Subsequently, required machineries and manpower and equipment for removal of debris were calculated. Finally, best practical methods for reduction and recycling were also examined. The shortest routes for transportation of post-earthquake to disposal sites were also proposed using network analysis. Results showed that about 83, 321 and 4802 million cubic meters of debris will be generated at 5, 6.5 and 7.5 $M_{\mathrm{W}}$, respectively. Disposal site of about $13 \mathrm{~km}^{2}$ is marked within the area of study for the management of debris. Preparedness, emergency operations, rehabilitation and reconstruction are among the main activities that can reduce the earthquakeinduced damages.
\end{abstract}

Keywords Debris depot - HAZUS - Network analysis · Post-earthquake $\cdot$ Management

A. R. Karbassi

akarbasi@ut.ac.ir

1 Department of Environmental Management, Graduate School of the Environment and Energy, Science and Research Branch, Islamic Azad University, Tehran, Iran

2 Graduate Faculty of Environment, University of Tehran, P.O. Box 14155-6135, Tehran, Iran

3 Department of Political Geography, University of Tehran, Tehran, Iran

\section{Introduction}

Earthquake could be the primary cause of the damage to structures, loss of life, and injuries (Bird and Bommer 2004; Edrissi et al. 2013). Consequences of earthquakes in urban areas that are prone to damage, necessitate risk assessment for development of mitigation plans (Erdik et al. 2005; Rafee et al. 2008; Mikoš et al. 2006). Such plans are vital for management and urgently responding to the crisis (Xu et al. 2014). Earthquake intensity is the most important factor in terms of damage production (Pramudita et al. 2014). A common challenge of all severe earthquakes is the generation of massive amounts of building debris. As reported by Xiao et al. (2012), a huge amount of building waste $\left(38,124.9 \times 10^{4} \mathrm{t}\right)$ was generated by collapsed dwelling houses after earthquake that occurred on May 12, 2008, in Sichuan Province in China. According to Inui et al. (2012), approximately 23 million tons of debris was generated as a result of the Pacific Coast of Tohoku Earthquake and tsunami.

The removal of huge amount of debris is a costly and complex operation that may take months or even years to complete (Pramudita and Taniguchi 2014). Poorly managed post-earthquake waste can have adverse environmental and public health impacts (Brown et al. 2011). Large amounts of building debris act as a major obstacle in relief operations (Coronado et al., 2011). The reconstruction process could also be hindered. In emergency situations, it is extremely important to secure traffic flow immediately. Chang et al. (2012) proposed a constructive heuristics to generate roadside debris cleanup plans for a limited number of equipment in the post-disaster road recovery planning issues (Ozdamar et al. 2014). Deaths caused by people pinned down under the wreckage in the Van earthquake on October 23, 2011, at 13:41 has been 
evaluated by (Hekimoglu et al. 2013). Experiences around the world show that a significant portion of the debris can be recycled and reused during the cleanup phases. In addition to economic benefits and savings, this will reduce the volume of the debris disposed into landfill sites.

Fetter and Rakes (2012) developed a decision support system with recycling incentives to locate temporary disposal sites; Hu and Sheu (2013) proposed on-site storage and treatment of debris to reduce risk-induced and psychological impacts of post-disaster debris.

Disaster management of the large post-earthquake waste is a real challenge for developing countries with inadequate technical and financial capacities (Karunasena et al. 2012). According to statistics, six percentages of the world's natural disasters occur in Iran, making the country one of the most prone areas in the world, especially regarding earthquakes (Amiri et al. 2013). Considering Iran's position in a seismic-prone region, the country has always been at risk of earthquakes with potentially catastrophic results (Omidvar et al. 2014). Mass volume of building debris, blocked passages, and damages on airport, electricity and telecommunication networks, and water distribution systems are only few issues reported after the large earthquakes in the country. There are clear evidences coming from the past severe earthquake observations to support this claim, including Bam earthquake at 05:26:56 local time (01:56:56 GMT) on Friday December 26, 2003 (Manafpour 2008), Manjil-Rudbar earthquake at 00:30:09 on June 21, 1990 (Berberian et al. 1992), Bou'in-Zahra earthquake (Asnafi and Pakdaman Naeini 2012), etc. Since the repetition of disasters is very likely, pre-crisis preparedness would be critical in mitigating possible losses (Ghodrati Amiri et al. 2007). Accordingly, the present study was carried out to formulate a comprehensive management plan for postearthquake debris disposal in Tehran Metropolitan City which is highly vulnerable to earthquakes.

\section{Materials and methods}

Tehran is the largest and capital city of Iran situated within the latitudes $51^{\circ} 02^{\prime}-51^{\circ} 36^{\prime} \mathrm{E}$ and the longitudes $35^{\circ} 34^{\prime}-$ $35^{\circ} 50^{\prime} \mathrm{N}$, over an approximate area of $730 \mathrm{~km}^{2}$. Tehran remains the world's twenty-fifth most populous city. According to the municipal division, Tehran is divided into 22 districts, 134 sub-districts (North Ray and Tajrish), and 370 neighborhoods. Regarding seismicity, the city is categorized among high-risk areas $\left(8^{\circ}-10^{\circ}\right.$ on the Mercalli scale). There are five major active faults in a radius of $150 \mathrm{~km}$ from the city center and suburbs, namely Mosha, North Tehran, Rey, Taleghan, and Eyvanakey. Historical data on earthquakes in Tehran reveal that the city has suffered from several severe earthquakes with a return period of 150 years. Considering that since the year 1830 the city has not experienced any catastrophic earthquake, seismologists warn of a severe earthquake in the near future taking into account the 35-year lag time over mean return period of 150 years.

In this research, HAZUS model was used to estimate possible post-earthquake damage and to calculate the extent of earthquake-induced debris at 22 districts of Tehran City. For this purpose, on-site impacts of earthquake were estimated by attenuation relationships, and damage occurrence probability was calculated based on fragility curves. Three sets of data such as the data on the target site, earthquake scenarios, and processing are needed to run the HAZUS model. The data on the number of building floors (short, intermediate, and tall buildings), structure systems (steel, reinforced concrete, all wood, cement blocks, and mixtures of brick, wood, and mud), building age, soil type (stone, hard alluvial, soft alluvial, and soft soil), and the location of faults (Mosha, North Tehran, and Rey) were gathered and archived for each 22 districts of Tehran City. Subsequently, three earthquake scenarios were designed under magnitudes of 5 , 6.5 , and 7.5 on the moment magnitude scale. These earthquakes are supposed to happen by the activation of the Ray, Mosha, and North Tehran faults.

According to the attenuation formula, the effect of earthquakes with the magnitude of $M$ at a point to the distance of $R$ from the center of the earthquake depends on soil characteristics, earthquake tectonic focus and finally the path of the seismic waves. In this research, attenuation equations of Campbell and Bozorgnia (1994) and Khademi (2002) were used to specify earthquake magnitude. Campbell and Bozorgnia (1994) used worldwide acceleration records of earthquakes with a magnitude of 4.7-8.1 torque to model strong ground motion as follows:

$$
\begin{aligned}
\ln (\mathrm{PGA})= & -3.512+0.904 M_{\mathrm{w}} \\
& -1.328 \ln \sqrt{R^{2}+\left[0.149 \exp \left(0.64 M_{\mathrm{w}}\right)\right]^{2}} \\
& +\left(1.125-0.112 \times \ln (R)-0.957 M_{\mathrm{w}}\right) \cdot F \\
& +(0.94-0.171 \ln (R)) S_{\mathrm{SR}} \\
& +0.405-0.222 \ln (R) \cdot S_{\mathrm{SR}}
\end{aligned}
$$

If $M \leq 7.4$;

$\sigma_{\mathrm{Ln}(\mathrm{PGA})}=0.889-0.0691 \mathrm{M}$

and if $\mathrm{M}>7.4$;

$\sigma_{\mathrm{Ln}(\mathrm{PGA})}=0.38$

$R$ the closest distance (less than $60 \mathrm{~km}$ ) to rupture in $\mathrm{km}$; $F$ is a parameter influenced by fault type so as for reverse and thrust faults $F=1 ; M_{\mathrm{W}}$ moment magnitude; $S_{\mathrm{SR}}$ is a site-affected parameter so as for soft site $S_{\mathrm{SR}=1}$, and for alluvial site $S_{\mathrm{SR}=0} ; S_{\mathrm{HR}}$ is a site-affected parameter so as for 
crystalline and metamorphic rocks $S_{\mathrm{HR}=1}$, and for alluvial sites $S_{\mathrm{HR}=0}$.

Khademi (2002) developed the following equation for Iran.

$Y=C_{1} \exp \left(C_{2} M\right)\left(R+C_{3} \exp \left(C_{4} M\right)\right)^{C_{5}}+C_{6} S$

The experimental-theoretical ground motion relation coefficients for different periods for vertical components and sites made of stones or soil, in fourteen periods from the time zero to the time $4 \mathrm{~s}$, for earthquakes with a magnitude from $M_{\mathrm{w}}=5$ to $M_{\mathrm{w}}=7.5$ and distance $r_{j b} \leq 150 \mathrm{~km}$ are as follows:

The coefficients of this equation are as follows:

$$
\begin{aligned}
& C_{1}=+0.040311, \quad C_{2}=+0.417342, \\
& C_{3}=+0.001000, \\
& C_{4}=+0.650000, \quad C_{5}=-0.351119, \\
& C_{6}=-0.035852,
\end{aligned}
$$

$S=0$ for stony sites, and $S=1$ for earthen sites

Fragility curves in HAZUS are modeled as a cumulative lognormal distribution, indicating the probability of reaching the excess of structural damage to the threshold of a given damage state.

$P\left[\left\langle d_{\mathrm{s}} S_{\mathrm{d}}\right\rangle\right]=\varphi\left[\frac{1}{\beta_{\mathrm{ds}}} \times \ln \left(\frac{S_{\mathrm{d}}}{\overline{S_{\mathrm{d}, \mathrm{ds}}}}\right)\right]$

$\bar{S}_{\mathrm{d}, \mathrm{ds}}$ : the median spectral displacement at which the structure reaches the threshold of the damage state (ds), $\beta_{\mathrm{ds}}$ : standard deviation of displacement logarithm related to the damage state (ds), $\varphi$ : standard normal cumulative distribution function.

A model called HAZUS was used for the prediction and estimation of the debris after earthquake. This model provides estimations for two kinds of debris:

1. The first kind is structural debris such as elements of steel or reinforced concrete.

2. The second kind is smaller debris such as irons, woods, bricks plastics, glasses and et cetera.

Estimation of debris could be done by the investigation of the following methods:

1. General Occupancy Class

2. Specific Occupancy Class

The amount of debris produced by the damage of buildings in metric tons depends on the following factors:

1. Weight of the structural and non-structural elements: For each of the sampled buildings, it is calculated based on tone per a thousand square foot.

2. The debris produced from the structural and nonstructural elements related to the situation in different phases of the damage caused by the earthquake
3. The first step in calculation of debris is to conflate the debris produced from the different regions of the damaged with the debris produced from different buildings

To estimate the weight of the debris of structural or nonstructural elements, the following formula based on ton per a thousand square feet is used:

$\operatorname{EDF}_{\mathrm{s}}(i, k)=\sum_{\mathrm{j}=2}^{5} P_{\mathrm{s}}(j, k) \times \mathrm{DF}_{\mathrm{s}}(i, j, k)$

$\operatorname{EDF}_{\mathrm{ns}}(i, k)=\sum_{j=2}^{5} P_{\mathrm{ns}}(j, k) \times \mathrm{DF}_{\mathrm{ns}}(i, j, k)$

$i$ : indicates the type of the debris; if $i=1$, then the debris is from woods, bricks, glasses or et cetera, and if $i=2$, then the debris is from elements of steel or reinforced concrete. $j$ : indicates the level of damage ranging from 1 to $5 . k$ : indicates the type of the building ranging from 1 to $36 . \mathrm{DF}_{\mathrm{s}}$ $(i, j, k)$ : indicates the amount of debris of type $i$, for building of type $k$ when the damage level is $j$ and it is obtained from the tables from (NIBS 2012). $P_{\mathrm{s}}(j, k)$ : indicates the probability of being situated in the damage level $j$ for a building of type $k . \operatorname{EDF}_{\mathrm{S}}(i, k)$ : indicates the debris of type $i=1$ caused by damage to a building of type $k$. $\operatorname{EDF}_{\mathrm{ns}}(i, k)$ : indicates the debris of type $i=2$ caused by damage to a building of type $k$.

These values indicate the percentage of the expected debris of type $i$, caused by structural or non-structural damage to the building of type $k$. If the values of $\mathrm{SQ}(k)$, $W_{\mathrm{s}}(i, k), W_{\mathrm{ns}}(i, k)$ are given by using statistics, the percentage of the expected debris is calculated from the following equation:

$$
\begin{aligned}
\mathrm{DB}(i)= & \sum_{\substack{k=1\\
}}^{36}\left[\mathrm{EDF}_{\mathrm{s}}(i, k) \times W_{\mathrm{s}}(i, k)+\operatorname{EDF}_{\mathrm{ns}}(i, k) \times W_{\mathrm{ns}}(i, k)\right] \\
& \mathrm{SQ}(k)
\end{aligned}
$$

$W_{\mathrm{s}}(i, k)$ : weight of structural debris of type $i$ per a thousand square feet. $W_{\mathrm{ns}}(i, k)$ : weight of non-structural debris of type $i$ per a thousand square feet. SQ $(k)$ : SQUARE foot of debris related to building of type $k$ per a thousand square feet.

The bare land areas within the 22 districts of Tehran were proposed as disposal sites for the building debris. After the occurrence of an earthquake, building debris should be transferred to the depot site through the shortest possible route in the shortest possible time. The most important factors in selection of evacuation routes sorted in the order of their importance are (1) invulnerability and sustainability of nearby buildings in the routes network, (2) inexistence of dangerous facilities or constructions, (3) low 
population density in construction blocks near the route network.

As the size of the resident population in blocks near the route network increases, its feasibility for optimum evacuation is reduced. In other words, routes with higher population density are less suitable for the optimization process of the routes.

Presence of bridges or tunnels across the evacuation routes can be dangerous or even very dangerous. Therefore, presence of bridges across these routes was strongly avoided or at least, the minimum requirements for securing and strengthening these bridges were fulfilled.

In this research, debris evacuation routes were designed using network analysis. Together with the main critical route network, consisting of freeways, highways, and main streets, a network of prioritized sub-routes was also plotted to further ease the access from the main routes to the target places in the city for relief and debris evacuation. To find the optimum way to transfer the debris to the proposed sites by the shortest routes and in the shortest possible time, the short pass and short time analyses were used. For this purpose, the center of gravity at each district was considered as the initial point (source) and the depot sites were assumed as the destination. In short pass analysis, it is necessary to take movement speed of different types of passages into account. The average speed limit on most highways and main streets in Tehran is 80 and $50 \mathrm{~km} / \mathrm{h}$, respectively. Accordingly, the average speed for highways and main streets is 60 and $30 \mathrm{~km} / \mathrm{h}$, respectively. The initial network system was modified by the experts familiar with the location using objective judgment analysis method. Subsequently, prioritized debris removal routes were specified using three criteria of net area of the district, the need of the district, and the impact of the old fabric. It is clear that the length of the critical paths at each district could be a function of its entire area defined as parameter $B$ (Eq. 7).

$B=\frac{L_{\text {c.r. }}}{A_{\mathrm{n}}}$

$L_{\text {c.r. }}$ is the length of the critical route, and $A_{\mathrm{n}}$ is net area of the district.

The need of the district is a function of its vulnerability. To quantify this criterion, the parameter c was defined as Eq. (8).

$c=\frac{T_{\mathrm{db}}}{A_{\mathrm{n}}}$

where $T_{\mathrm{db}}$ is the total of damaged buildings, and $A_{\mathrm{n}}$ is the net area of the district.

As it is evident, extended areas of old urban fabric at each district will increase the length of routes prioritized to be reopened urgently. To determine the effect of old fabric,
$J$ parameter was defined according to Eq. (9) in which the $U f$ parameter addresses the area of old fabric in each district in percentage.

$J=C \times(1+2 \times U f)$

\section{Results and discussion}

According to the HAZUS results, in the event of a 5-magnitude earthquake on Rey Fault, the debris volume would be about $182,668,536 \mathrm{~m}^{3}$. As a result of this earthquake, $21 \%$ of Tehran's buildings will be destroyed and about 1,818,121 people will be made homeless. Furthermore, the casualties are estimated at 5907, and also 194,047 people will be injured. Damage to the $8 \%$ of the buildings, over an area of 71,079,968 $\mathrm{m}^{2}$, is assessed as heavy. Approximately $13 \%$ of the buildings over an area of $10,043,744 \mathrm{~m}^{2}$ will suffer moderate damage. The remaining buildings (about $57 \%$ over an area of $372,354,272 \mathrm{~m}^{2}$ ) will stay almost intact after the earthquake. The 6.5-magnitude earthquake on Rey Fault will generate about $3,211,338,400 \mathrm{~m}^{3}$ of debris and leave 329,354 residents injured, 14,910 killed, and 2,984,685 homeless. It will also heavily demolish $24 \%$ of the buildings over an area of $128,852,112 \mathrm{~m}^{2}$. The damage to the $21 \%$ of the buildings in an area of $190,317,808 \mathrm{~m}^{2}$ is estimated to be average, while in an area of $202,796,272 \mathrm{~m}^{2}$ covering $22 \%$ of the entire city area will be slight. Approximately $33 \%$ of the total buildings over an area of $112,397,824 \mathrm{~m}^{2}$ would not be damaged. According to the results, it is expected that $4,802,307,200 \mathrm{~m}^{3}$ of debris will be produced if an earthquake of 7.5 magnitude occurs. As a result, $54 \%$ of buildings will be damaged and 3,306,104 residents lose their homes. This is coupled with 190,510 casualties and also 363,442 injuries.

The 7.5-magnitude earthquake can heavily damage $23 \%$ of buildings over an area of 194,082,104 $\mathrm{m}^{2}$. The damage to $21 \%$ of the buildings, within an area of $194,179,104 \mathrm{~m}^{2}$, is estimated average. About $19 \%$ of the buildings will undergo minor damage. The remaining buildings $(28 \%$ of the total, over an area of $90,534,912 \mathrm{~m}^{2}$ ) will remain intact.

In the event of a 5-magnitude earthquake on Mosha Fault, a total debris of $6,972,296,192 \mathrm{~m}^{3}$ would be generated that is resulted from damages to $18 \%$ of buildings. This earthquake leaves 2,760,103 people homeless. Casualties and injuries will be around 6709 and 277,932, respectively. Approximately $6 \%$ of the buildings, over an area of $52,013,408 \mathrm{~m}^{2}$, are highly vulnerable to the earthquake. The damage to the $12 \%$ of the buildings, within an area of $100,685,088 \mathrm{~m}^{2}$, is estimated as an average. More than $23 \%$ of the buildings covering an area of 206,914,592 


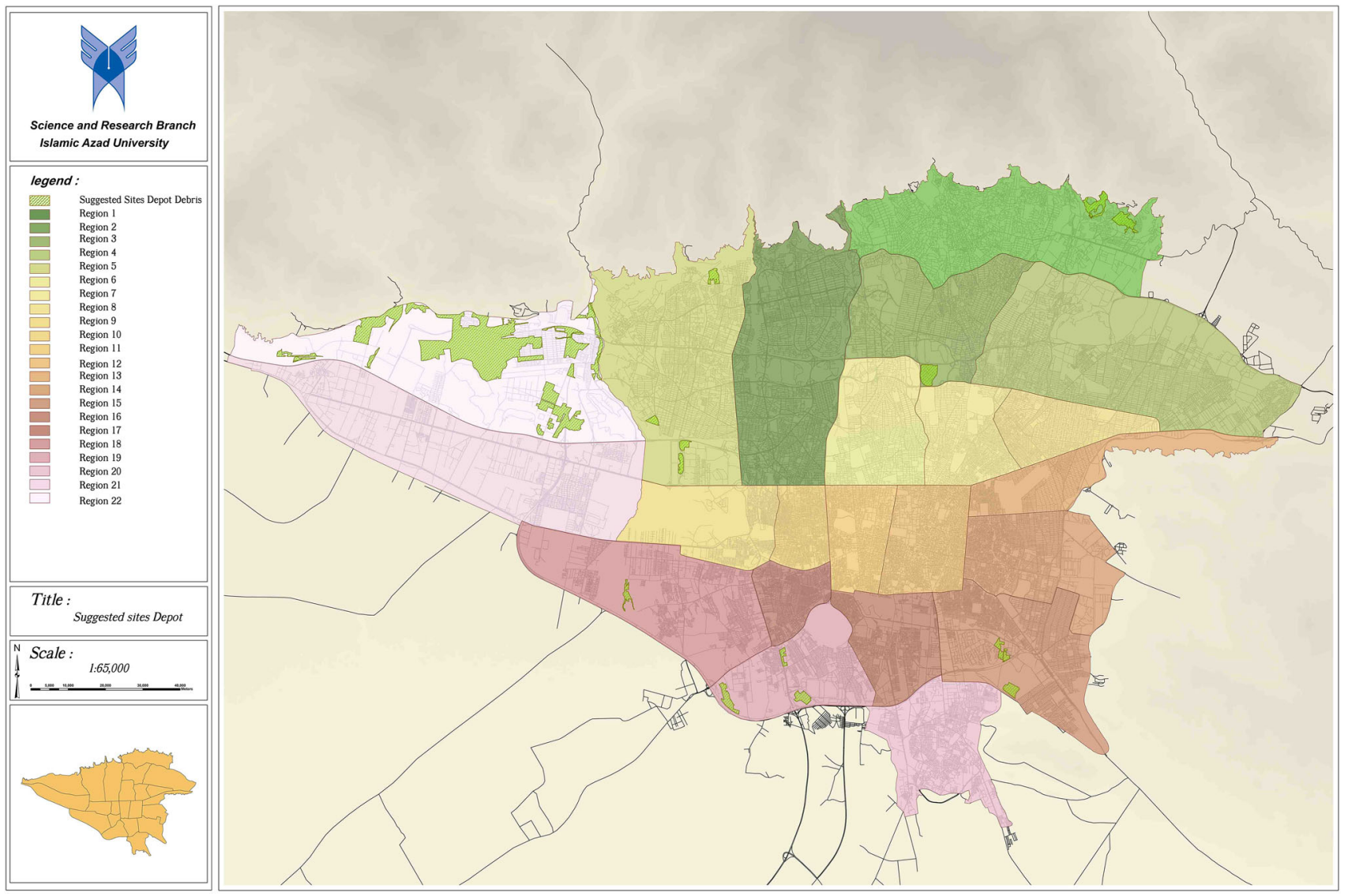

Fig. 1 Distribution of depot sites for the disposal of post-earthquake debris in Tehran

will be slightly damaged. About $50 \%$ of the buildings are expected to remain intact after the earthquake. An estimated 9,451,494,656 $\mathrm{m}^{3}$ of debris will be produced after a 6.5-magnitude earthquake on Mosha Fault causing $30 \%$ of the buildings damaged. The death toll of the earthquake will reach 13,199, and the number of the injured will be 415,746 . Overall, $12 \%$ of the buildings $\left(114,606,256 \mathrm{~m}^{2}\right)$ will be destroyed heavily, $18 \%\left(152,219,344 \mathrm{~m}^{2}\right)$ moderately, and $25 \%\left(221,405,712 \mathrm{~m}^{2}\right)$ slightly. Approximately $45 \%\left(246,132,736 \mathrm{~m}^{2}\right)$ of the buildings are expected to remain intact. In case of a 7.5-magnitude earthquake on Mosha Fault, about 12,106,525,697 $\mathrm{m}^{3}$ of debris will be generated as a result of the destruction of $53 \%$ of the buildings. The number of earthquake casualties will reach 17,154. A total number of $3,257,441$ and 363,334 will be homeless and injured, respectively. Furthermore, damage to $30 \%\left(276,702,144 \mathrm{~m}^{2}\right)$ of buildings is estimated to be heavy, $23 \%\left(194,179,104 \mathrm{~m}^{2}\right)$ is moderate, and $19 \%$ $\left(171,639,952 \mathrm{~m}^{2}\right)$ is slight. There will not be any damage to $28 \%\left(91,832,832 \mathrm{~m}^{2}\right)$ of the buildings.

A 5-magnitude earthquake induced by North Tehran Fault will result in $24,256,800 \mathrm{~m}^{3}$ of debris that is the result of collapse of $9 \%$ of buildings. This will lead to the death of 1413 residents and the injury of 78,843 people. About 910,747 people will be homeless. Around $2 \%$ $\left(27,376,642 \mathrm{~m}^{2}\right)$ of the buildings will undergo severe damage and $7 \%\left(63,859,956 \mathrm{~m}^{2}\right)$ will suffer moderate damage. The damage to $17 \%\left(163,839,200 \mathrm{~m}^{2}\right)$ is estimated to be slight, while about $74 \%\left(479,288,256 \mathrm{~m}^{2}\right)$ will remain intact. The estimated debris after a 6.5 -magnitude earthquake on North Tehran Fault will reach $712,023,376 \mathrm{~m}^{3}$. In the event of the earthquake, $28 \%$ of the buildings are expected to be destroyed, leaving 2,093,908 people homeless. Among other post-earthquake impacts, the death of 6190 residents and the injury of 218,315 people can be pointed out. The damage to the $25 \%\left(133,434,592 \mathrm{~m}^{2}\right)$ of buildings is heavy, $16 \%$ $\left(154,631,856 \mathrm{~m}^{2}\right)$ is average, and $12 \%\left(226,025,472 \mathrm{~m}^{2}\right)$ is slight. About $47 \%$ of the buildings in an area of $220,272,096 \mathrm{~m}^{2}$ will remain intact.

The 7.5-magnitude earthquake on North Tehran Fault will generate $953,407,968 \mathrm{~m}^{3}$ debris, resulting from the collapse of $36 \%$ of buildings. The number of injuries and death toll will be as many as 15,108 people and 479,813 


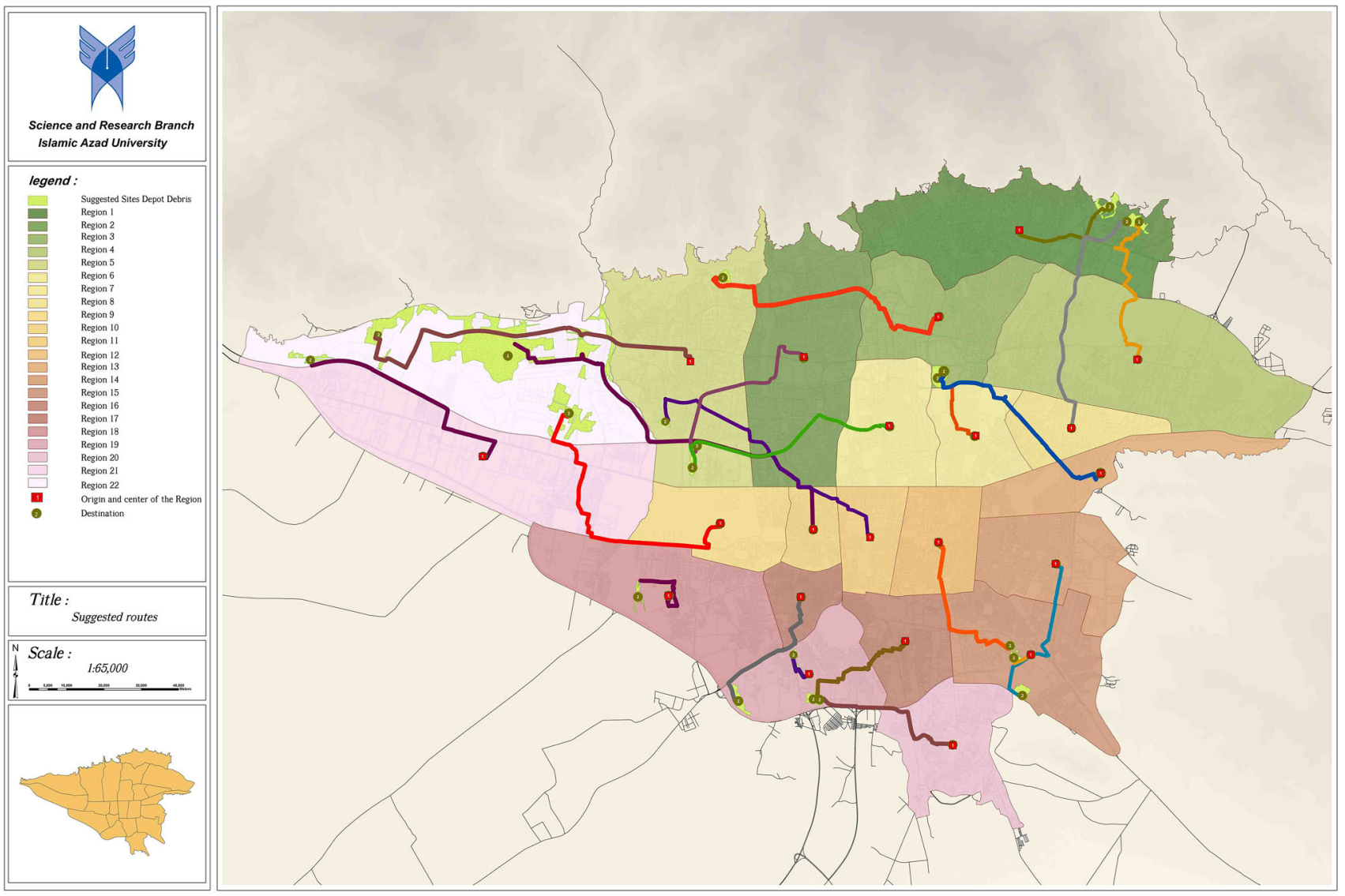

Fig. 2 Routes of debris evacuation in Tehran

people, respectively. Quake-related damage is evaluated heavy in $15 \%$ of buildings over an area of $160,049,920 \mathrm{~m}^{2}$, average in $21 \%$ of buildings over an area of $202,136,624 \mathrm{~m}^{2}$, and slight in $26 \%$ of buildings over an area of $232,451,872 \mathrm{~m}^{2}$. Furthermore, the damage to $38 \%$ of the buildings within an area of $139,725,632 \mathrm{~m}^{2}$ is negligible.

Once estimating the magnitude of debris and extent of the damage, unoccupied lands in the city were allocated as debris depot sites. Figure 1 depicts distribution of the depot sites in Tehran. According to the results, the western part of Tehran accounts for the largest depot area of $12,039,252 \mathrm{~m}^{2}$. The depot area of $2,231,875.426 \mathrm{~m}^{2}$ is stretched in south. The area of the depot sites in the central and northern Tehran is about $1,209,261.047 \mathrm{~m}^{2}$. They also cover an area of $974,599.1406 \mathrm{~m}^{2}$ in the east of Tehran.

Debris removal and evacuation operations after the earthquake are necessary to eliminate possible threats or potential dangers, as well as for the reconstruction phase to ensure safety and security of people. Determining debris deposit and evacuation spaces is one of the most important urban management factors in dealing with an earthquake crisis which should be done according to the population density and the reachability of the location (Abbasi and Farbod 2009).

In this study, arid lands in the 22 districts of Tehran were determined for evacuation and temporary deposition of the debris where the debris will be recycled for an interval of time or it will be sent to the outside of the city for burial.

Considering the volume of debris and the constraint of cleaning and reopening operations, waste disposal routes should be as short as possible. Accordingly, network analysis was used to determine the debris removal routes by finding shortest possible paths between the center of gravity at various districts as the starting point and the depot sites as destination. Figure 2 demonstrates the routes of the debris evacuation in Tehran.

Debris Removal Specialized Committee (DRSC) is in charge of post-earthquake crisis management in Tehran. About 200, 160 and $80 \mathrm{~m}^{3}$ /building has been computed as 


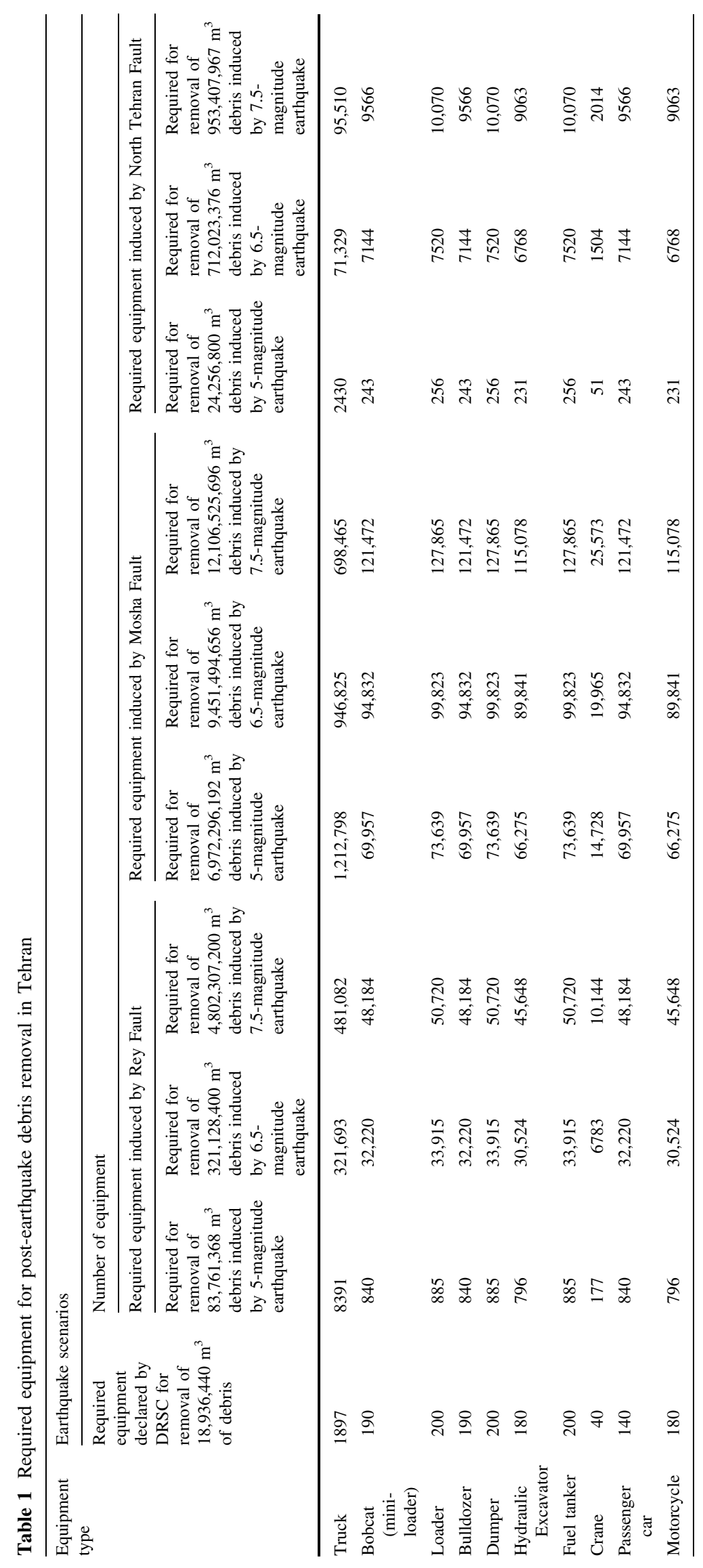




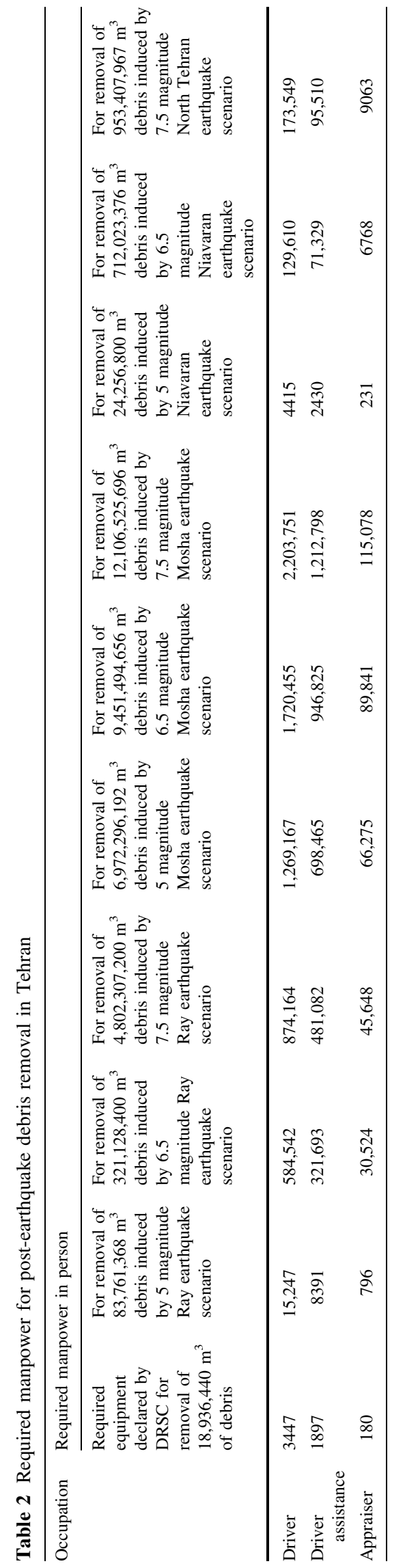

average volume of debris by DRSC for complete, heavy and moderate destruction of Tehran's building. Considering the time required for loading and transportation between the starting points and the depot sites, each truck would be capable of eight services a day to evacuate a volume of $5 \mathrm{~m}^{3}$ per each service (or $40 \mathrm{~m}^{3} /$ day). In order to estimate the required equipment for loading and transportation of debris and trash to the temporary depot sites, the following assumptions were considered:

1. Loading time is $1 \mathrm{~h}$

2. Up and down travel time between the districts and temporary depot sites is $2 \mathrm{~h}$

3. It is assumed that a 5-t trucks will be used to transport rubble and debris and that any truck can offer eight services in $24 \mathrm{~h}$

4. Cleaning period is about 3 months

5. Considering a total capacity of 5 tons per truck, each truck can transport 40 t/day.

Accordingly, the required equipment for each earthquake scenarios was estimated. Table 1 presents the required equipment for the most likely earthquake scenario (5-, 6.5-, and 7.5-magnitude earthquake on Mosha, North Tehran, and Rey Fault).

The figures presented in Tables 1 and 2 are indicative of significant number of machineries and manpower. In other words, the existing capability is only about $3.22 \%$ real needs.

\section{Conclusion}

The present work brought out an estimation on postearthquake debris volume in Tehran Metropolitan City. In order to reduce the earthquake-induced damages in the city, stringent efforts must be made in four stages. These include (1) preparedness (for planning to reduce damage in the event of an earthquake), (2) emergency operations (to mobilize relief operations, immediate and effective evacuation, and other necessary post-earthquake activities), (3) rehabilitation (to restore the vital passages of the city centers as soon as possible without compromising the security of the people), and (4) reconstruction (to reconstruct urban fabric in way to further withstand future earthquakes). Adequate funding is needed to support preparedness, emergency operations, rehabilitation, and reconstruction strategies. To fulfill these objectives, it is necessary to impose stricter building construction rules particularly for high-rise buildings in Tehran, with more emphasize on crisis management approaches. As another important management strategy, straightening and integration of spatial databases can further facilitate the early relief and rescue operations throughout Tehran City. 
Finally, it has been suggested to enhance capabilities of the current Tehran Earthquake Damage Estimation System (TEDES) for rapid estimation of earthquake-induced losses at the moment of the occurrence and to stimulate earthquake scenarios. This can help prioritizing building retrofit projects at different districts of the city and provide the crisis managers with the opportunity of wise decisionmaking.

Acknowledgments We greatly thank municipality of Tehran for supporting the Ph.D. student under the Fund No. MUP.Ph.D.12.

\section{References}

Abbasi MR, Farbod Y (2009) Faulting and folding in quaternary deposits of Tehran's Piedmont (Iran). J Asian Earth Sci 34:522-531

Amiri M, Chaman R, Raei M, Shirvani SDN, Afkar A (2013) Preparedness of hospitals in north of Iran to deal with disasters. Iran Red Crescent Med J 15(6):519-521

Asnafi AR, Pakdaman Naeini M (2012) Buin-Zahra earthquake: an archival approach. Res Bull Seismol Earthq Eng 15(2):47-55 (Special Issue)

Berberian M, Qorashi M, Jackson JA, Priestley K, Wallace T (1992) The Rudbar-Tarom earthquake of 20 June 1990 in NW Persia: preliminary field and seismological observations, and its tectonic significance. Bull Seismol Soc Am 82(4):1726-1755

Bird JF, Bommer JJ (2004) Earthquake losses due to ground failure. Eng Geol 75(2):147-179

Brown Ch, Milke M, Seville E (2011) Disaster waste management: a review article. Waste Manag 31(6):1085-1098

Campbell KW, Bozorgnia Y (1994) Empirical analysis of strong motion from the 1992 Landers, California, earthquake. Bull Seismol Soc Am 84(3):573-588

Chang L, Elnashai AS, Spencer BF Jr (2012) Post-earthquake modelling of transportation networks. Struct Infrastruct Eng 8(10):893-911

Coronado M, Dosal E, Coz A, Viguri JR, Andres A (2011) Estimatiom of construction and demolition waste(C\&DW) generation and multicriteria analysis of C\&DW management alternatives: a case study in Spain. Waste Biomass Valor 2:209-225

Edrissi A, Poorzahedy H, Nassiri H, Nourinejad M (2013) A multiagent optimization formulation of earthquake disaster prevention and management. Eur J Oper Res 229(1):261-275

Erdik M, Rashidov T, Safak E, Turdukulov A (2005) Assessment of seismic risk in Tashkent, Uzbekistan and Bishkek, Kyrgyz Republic. Soil Dyn Earthq Eng 25(7-10):473-486

Fetter G, Rakes T (2012) Incorporating recycling into post-disaster debris disposal. Socio-Econ Plan Sci 46(1):14-22

Ghodrati Amiri G, Mahdavian A, Dana FM (2007) Attenuation relationships for Iran. J Earthq Eng 11(4):469-492

Hekimoglu Y, Melez IE, Canturk G, Erkol Z, Canturk N, Dizdar MG, Melez DO, Guler OM (2013) Evaluation of the deaths secondary to entrapment under the debris in the Van earthquake. Egypt $\mathrm{J}$ Forensic Sci 3(2):44-47

Hu Z-H, Sheu J-B (2013) Post-disaster debris reverse logistics management under psychological cost minimization. Transp Res Part B Methodol 55:118-141

Inui T, Yasutaka T, Endo K, Katsumi T (2012) Geo-environmental issues induced by the 2011 off the Pacific Coast of Tohoku Earthquake and tsunami. Soils Found 52(5):856-871

Karunasena G, Amaratunga D, Haigh R (2012) Post-disaster construction \& demolition debris management: a Sri Lanka case study. J Civ Eng Manag 18(4):457-468

Khademi MH (2002) Attenuation of peak and spectral accelerations in the Persian plateau. In: Proceedings of Twelfth European Conference on Earthquake Engineering. Barbican Centre, London

Manafpour AR (2008) Ban Earthquake, Iran: Lessons on the seismic behavior of building structures. In: The 14th World Conference on Earthquake Engineering, Beijing, 12-17 Oct 2008

Mikoš M, Fazarinc R, Ribičič M (2006) Sediment production and delivery from recent large landslides and earthquake-induced rock falls in the Upper Soča River Valley. Slov Eng Geol 86(2-3):198-210

National Institute of Building Science (NIBS) (2012) HAZUS 99 technical and user's manual, Washington DC, USA, Federal Emergency Management Agency (FEMA)

Omidvar B, Golestaneh M, Abdollahi Y (2014) A framework for post-earthquake rapid damage assessment of hospitals. Case study: Rasoul-e-Akram Hospital (Tehran, Iran). Environ Hazards 13(2):133-160

Ozdamar L, Tuzun AD, Erguneş B (2014) Coordinating debris cleanup operations in post disaster road networks. Socio-Econ Plan Sci 48(4):249-262

Pakdaman NM, Asnafi AR (2012) Buin-Zahra earthquake: an archival approach. Res Bull Seismol Earthq Eng 15(2):47-55

Pramudita A, Taniguchi E (2014) Model of debris collection operation after disasters and its application in urban area. Int $\mathbf{J}$ Urban Sci 18(2):2168-2243

Pramudita A, Taniguchi E, Qureshi AG (2014) Location and routing problems of debris collection operation after disasters with realistic case study. Soc Behav Sci 125:445-458

Rafee N, Karbassi AR, Nouri J, Safari E, Mehrdadi M (2008) Strategic management of municipal debris aftermath of an earthquake. Int J Environ Res 2(2):205-214

Shoja-Taheri J, Naserieh S, Ghofrani H (2007) ML and MW scalein the Iranian Pelateau base on the strong motion records. Bull Seism Soc Am 97(2):661-669

Veneziano D, Sussman JM, Gupta U, Kunnumkal SM (2002) Earthquake loss under limited transportation capacity: assessment, sensitivity and remediation. In: 7th US National Conference on Earthquake Engineering, Boston, MA, EERI

Wang CY, Hu SR (2005) A study on emergency evacuation and rescue network reconstruction for natural disasters with multiclass travel behavior constraints. J East Asian Soc Transp Stud 6:4269-4284

Werner SD, Taylor CE (2002) Component vulnerability modeling issues for analysis of seismic risks to transportation lifeline systems. In: Werner SD, Taylor CE (eds) Acceptable risk processes: lifelines and natural hazards, Monograph No. 21, 
Technical Council on Lifeline Earthquake Engineering, ASCE, Reston

Xiao J, Xie H, Zhang Ch (2012) Investigation on building waste and reclaim in Wenchuan earthquake disaster area. Resour Conserv Recycl 61:109-117
$\mathrm{Xu} \mathrm{J}$, Nyerges TL, Nie G (2014) Modeling and representation for earthquake emergency response knowledge: perspective for working with geo-ontology. Int J Geogr Inf Sci 28(1):185-205 